\title{
Solar and geomagnetic activity effects on mid-latitude F-region electric fields
}

\author{
V. V. Kumar, M. L. Parkinson, P. L. Dyson, and R. Polglase \\ Department of Physics, La Trobe University, Melbourne, Victoria, 3086, Australia \\ Received: 25 March 2008 - Revised: 7 August 2008 - Accepted: 27 August 2008 - Published: 24 September 2008
}

\begin{abstract}
Diurnal patterns of average F-region ionospheric drift (electric field) and their dependence on solar and geomagnetic activity have been defined using digital ionosonde Doppler measurements recorded at a southern mid-latitude station (Bundoora $145.1^{\circ} \mathrm{E}, 37.7^{\circ} \mathrm{S}$ geographic, $49^{\circ} \mathrm{S}$ magnetic). A unique database consisting of 300907 drift velocities was compiled, mostly using one specific mode of operation throughout 1632 days of a 5-year interval (19992003). The velocity magnitudes were generally larger during the night than day, except during the winter months (JuneAugust), when daytime velocities were enhanced. Of all years, the largest drifts tended to occur during the high speed solar wind streams of 2003. Diurnal patterns in the average quiet time ( $\mathrm{AE}<75 \mathrm{nT})$ meridional drifts (zonal electric field) peaked at up to $\sim 6 \mathrm{~m} \mathrm{~s}^{-1}$ poleward $\left(0.3 \mathrm{mV} \mathrm{m}^{-1}\right.$ eastward $)$ at 03:30 LST, reversing in direction at $\sim 08: 30$ LST, and gradually reaching $\sim 10 \mathrm{~m} \mathrm{~s}^{-1}$ equatorward at $\sim 13: 30 \mathrm{LST}$. The quiet time zonal drifts (meridional electric fields) displayed a clear diurnal pattern with peak eastward flows of $\sim 10 \mathrm{~m} \mathrm{~s}^{-1}$ $\left(0.52 \mathrm{mV} \mathrm{m}^{-1}\right.$ equatorward) at 09:30 LST and peak westward flows around midnight of $\sim 18 \mathrm{~m} \mathrm{~s}^{-1}\left(0.95 \mathrm{mV} \mathrm{m}^{-1}\right.$ poleward). As the $\mathrm{AE}$ index increased, the westward drifts increased in amplitude and they extended over a greater fraction of the day. The perturbation drifts changed in a similar way with decreasing $D_{s t}$ except the daytime equatorward flows strengthened with increasing $\mathrm{AE}$ index, whereas they became weak for $D_{s t}<-60 \mathrm{nT}$. The responses in all velocity components to changing solar flux values were small, but net poleward perturbations during the day were associated with large solar flux values $\left(>192 \times 10^{-22} \mathrm{~W} \mathrm{~m}^{-2} \mathrm{~Hz}^{-1}\right)$. These results help to more fully quantify the response of the midlatitude ionosphere to changing solar and geomagnetic conditions, as required to refine empirical and theoretical models of mid-latitude electric fields.
\end{abstract}

Correspondence to: V. V. Kumar

(v.kumar@latrobe.edu.au)
Keywords. Ionosphere (Ionospheric disturbances; Midlatitude ionosphere; Plasma convection)

\section{Introduction}

Comprehensive reviews of the work done in identifying various channels through which momentum and energy are transferred from the solar wind to the different regions of Geospace are given in Kelley (1989) and Hargreaves (1992). The dynamics of the F-region ionosphere are controlled by many coupled processes involving production and loss of plasma, electromagnetic forces, thermospheric neutral winds, pressure gradients, and diffusion (e.g. Kelley, 1989; Hargreaves, 1992; Fejer, 1993). These phenomena are affected by variability in the solar flux, solar wind, and magnetic substorms and storms. The most intense magnetospheric effects occur at high-latitudes but they sometimes penetrate to low-latitudes, especially when the changes in the solar wind and magnetosphere are rapid.

In the high-latitude ionosphere, plasma flow is dominated by the Volland-Stern-two-cell convection pattern (Weimer, 1995) which is driven by the externally applied magnetospheric potential (Heelis, 2004). When there are rapid increases in the solar wind density and speed, the dayside magnetosphere is compressed. When the interplanetary magnetic field (IMF) also turns southward, magnetometer signatures of storm sudden commencement (SSC) may occur. Increased magnetic reconnection on the dayside magnetopause causes increased Poynting flux into the ionosphere and enhanced magnetospheric convection. This is accompanied by, an equatorward expansion of the auroral oval, enhanced energetic particle precipitation, and thus increased ionospheric conductivity and Joule heating which lead to stronger neutral winds (Fejer et al., 2000).

Perturbations in the thermospheric winds produce additional electric fields by the dynamo effect, the familiar

Published by Copernicus Publications on behalf of the European Geosciences Union. 
consequence of ion-neutral collisions in the presence of a magnetic field (Buonsanto, 1999). These electric fields, in turn, affect the neutrals and plasma alike (e.g. Heelis, 2004), hence illustrating the close coupling between the ionized and neutral components of the upper atmosphere. It is necessary to consider the role of the neutral atmosphere to understand many storm-time effects (Buonsanto, 1999; Fejer et al., 2000).

Clearly, the inner magnetosphere and sub-auroral ionosphere play an important role in substorm and storm processes. Intense $\boldsymbol{E} \times \boldsymbol{B} / B^{2}$ plasma convection in the subauroral ionosphere causes enhanced recombination and contributes to ionospheric trough formation (Vo and Foster, 2001). In the region $\sim 50-65^{\circ} \Lambda$ (magnetic latitude), steep gradients in plasma density associated with the ionospheric trough and advecting plasma density enhancements during magnetic storms have been recorded using incoherent scatter radar (ISR) data (Vo and Foster, 2001; Foster and Vo, 2002). Particle precipitation is usually weak at mid-latitudes, but strong magnetospheric electric fields can penetrate during under and over shielding conditions (Fejer, 2002).

Quiet and disturbed time electric fields in the mid- and low-latitude ionosphere have been extensively studied in the last two decades using ISRs and satellites (e.g. Wand and Evans, 1981; Blanc, 1983; Buonsanto et al., 1993; Fejer, 1993; Foster and Rich, 1998). The ISR studies have used observations made at Arecibo $\left(18^{\circ} \mathrm{N}\right.$ geographic, $31^{\circ} \mathrm{N}$ magnetic) (e.g. Behnke and Harper, 1973; Fejer, 1993), Saint-Santin $\left(45^{\circ} \mathrm{N}\right.$ geographic, $40^{\circ} \mathrm{N}$ magnetic) (e.g. Blanc, 1983; Buonsanto and Witasse, 1999; Scherliess et al., 2001); and Millstone Hill ( $43^{\circ} \mathrm{N}$ geographic, $57^{\circ} \mathrm{N}$ magnetic) (e.g. Evans, 1972; Buonsanto et al., 1993; Foster and Vo, 2002).

Scherliess and Fejer (1998) used Dynamics Explorer II spacecraft measurements to determine empirical models of equatorial and mid-latitude electric fields. Scherliess et al. (2001) also determined empirical models of mid-latitude electric fields using Millstone Hill and Saint-Santin ISR observations. They also determined the storm time dependence of prompt penetration and longer lasting perturbation drifts, and their results were in basic agreement with the DE II results, as well as predictions made using the theoretical Rice Convection Model (Spiro, 1988).

Ongoing studies of the effects of geomagnetic storms on mid-latitudes are essential because they are an important link in the complex chain of solar-terrestrial relations which ultimately affect human civilisation. Although the preceding studies explain the major features of the observations, the day-to-day and storm-to-storm variability is large, and there are significant unexplained differences between the stations and models. The analysis of observations made at many locations around the world is required to help refine the models. Our knowledge of thermospheric tides, winds and ionospheric motion (and turbulence) on global scales is still incomplete.
Parkinson et al. (2001) reported the analysis of 1-year of digital ionosonde F-region Doppler drifts collected at the Southern Hemisphere mid-latitude station Bundoora $\left(37.7^{\circ} \mathrm{S}\right.$ geographic, $49^{\circ} \mathrm{S}$ magnetic). They interpreted the velocities as the effects of ion drifts (electric fields) and calculated diurnal patterns in the average field-perpendicular components, and their dependence on season and the $K_{p}$ index. The present study builds upon the earlier work of Parkinson et al. (2001) using a more extensive database covering the 5year interval 1999 to 2003. Moreover, we sort and average the data according to the 1-min AE index, hourly $D_{s t}$, and daily $10.7-\mathrm{cm}$ solar radio flux. The average response of midlatitude F-region during geomagnetically quiet and disturbed conditions are more fully quantified using these improved indices, and new features are identified. This study is important because future models of mid-latitude electric fields will need to incorporate the effects of changing solar flux, solar wind and IMF conditions, substorms, storms, and their complicated variations with geographic location and local time.

\section{Instrument and database}

This study uses data recorded with a vertical incidence HF digital ionosonde known as the Digital Portable Sounder 4 (DPS-4) (Reinisch, 1986) located at Bundoora, Melbourne. The DPS-4 records digital ionograms with moderate Doppler resolution as well as high Doppler resolution drift data (Scali et al., 1995). The latter technique is also known as Doppler sorted interferometry (DSI) (e.g. Parkinson et al., 1999). For the measurements analysed in this paper, the DPS-4 recorded ionograms by scanning in frequency for less than 2 min once every $10 \mathrm{~min}$. During the intervening $8 \mathrm{~min}$, DSI measurements were made using $o$-mode polarisation at licensed fixed frequencies. Typical daytime (21:00-09:00 UT) DSI sounding frequencies were 4.449 or $5.480 \mathrm{MHz}$, and the night time (09:00-21:00 UT) frequency was $3.399 \mathrm{MHz}$. For the majority of this study, a low PRF of $50 \mathrm{~Hz}$ was used to form $128 \mathrm{el}-$ ement time series of length $40.96 \mathrm{~s}$ on all four antennas. This gave a Doppler resolution of $24.4 \mathrm{mHz}(\Delta T \Delta f=1)$ and a corresponding Nyquist frequency of $\pm 1.5625 \mathrm{~Hz}$. More details about the Bundoora DPS-4 and its operating modes have been given by Parkinson et al. (1999, 2001).

The standard Digisonde Drift Analysis (DDA) software (Scali, 1993) was used to analyse the DSI measurements and calculate the 3-D drift velocity in a Cartesian reference frame. The drift velocities were then transformed into components perpendicular (poleward directed, $V_{\perp P}$; eastward directed $V_{\perp E}$ ) and parallel to the geomagnetic field $\left(\boldsymbol{V}_{\mid}\right)$using Eqs. (1) to (3) of Parkinson et al. (2001) and a magnetic dip angle of $69^{\circ}$. Equivalent electric fields were then calculated using $E=-V \times B$, with $B=54.742 \mu \mathrm{T}$ at $L=2.4$ in the F-region above Bundoora.

Parkinson et al. (2001) found that $V_{\perp P}$ and $\boldsymbol{V}_{\mid}$tend to be anti-correlated, a familiar feature in mid-latitude ISR 
measurements which arises due to coupling between the neutral wind and ion drift (e.g. Behnke and Harper, 1973; Buonsanto et al., 1993). Hence in this paper we focus on the fieldperpendicular velocity components and corresponding electric fields. We note that $V_{\perp P}$ and $V_{\mid}$tend to adjust to keep the meridional flow within the horizontal plain (i.e. like the zonal flow). Throughout this paper we refer to $V_{\perp P}$ as a poleward flow, even though strictly it is a poleward and upward flow at mid-latitudes.

DDA was used to estimate one 3-D drift velocity for each $40.96 \mathrm{~s}$ integration. Velocities were rejected if the DDA standard errors in vertical and horizontal components, and azimuths exceeded $50 \mathrm{~ms}^{-1}, 250 \mathrm{~m} \mathrm{~s}^{-1}$ and $90^{\circ}$, respectively. These larger errors were concentrated during intervals of poor signal-to-noise ratio and low echo detection rate. Echoes with zenith angles greater than $45^{\circ}$ were also excluded to reduce angle-of-arrival ambiguities and help ensure homogeneity of the overhead velocity field. Echoes with virtual heights below $180 \mathrm{~km}$ were classified as E-region data and rejected.

After applying these filters, the database consisted of 300907 F-region drift velocities, mostly obtained using a single mode of operation of the DPS-4 throughout 1632 days during the 5-year interval 23 February 1999 to 7 December 2003. A summary plot the entire database is given in Fig. 1 where the results were averaged on the time scale of the solar rotation period, 27-days. The study interval encompasses the ascending phase of the solar cycle during 1999, the sunspot maximum years 2000-2001, and the declining phase years of 2002-2003.

Figure 1a shows the 27-day running average of the daily $10.7-\mathrm{cm}$ solar radio flux (black) and hourly- $D_{s t}$ index (red). There is an association between increases in solar activity and decreases in the $D_{s t}$ index, but the decreases in $D_{s t}$ sometimes lag the increases in solar flux. However, during 2003 the solar flux plummeted but the $D_{s t}$ index remained weakly negative $(\sim-20 \mathrm{nT})$. This is due to the high speed solar wind streams known to re-occur during the declining phase of solar activity (e.g. Cliver et al., 1996).

Figure 1b shows the 27-day running count of DPS-4 echoes (black) and average $\mathrm{AE}$ index (red). The primary maximum in the AE index was observed during 2003 and was also associated with the aforementioned high speed streams. The generation of ionospheric irregularities might be enhanced with geomagnetic activity, but the echo counts were only weakly correlated with AE. Note that the echo counts were also related to the measurement process. For example, an examination of ionograms showed the peak plasma frequency foF2 sometimes dropped beneath the chosen fixed frequency because the ionospheric trough moves above the station, negative storm effects, or depressed levels of daytime solar UV and X-rays.

Figure $1 \mathrm{c}$ and d shows, respectively, the average magnitude and azimuth of the velocity perpendicular to geomagnetic field $\left(V_{\perp}\right)$. The azimuth angle is measured positive

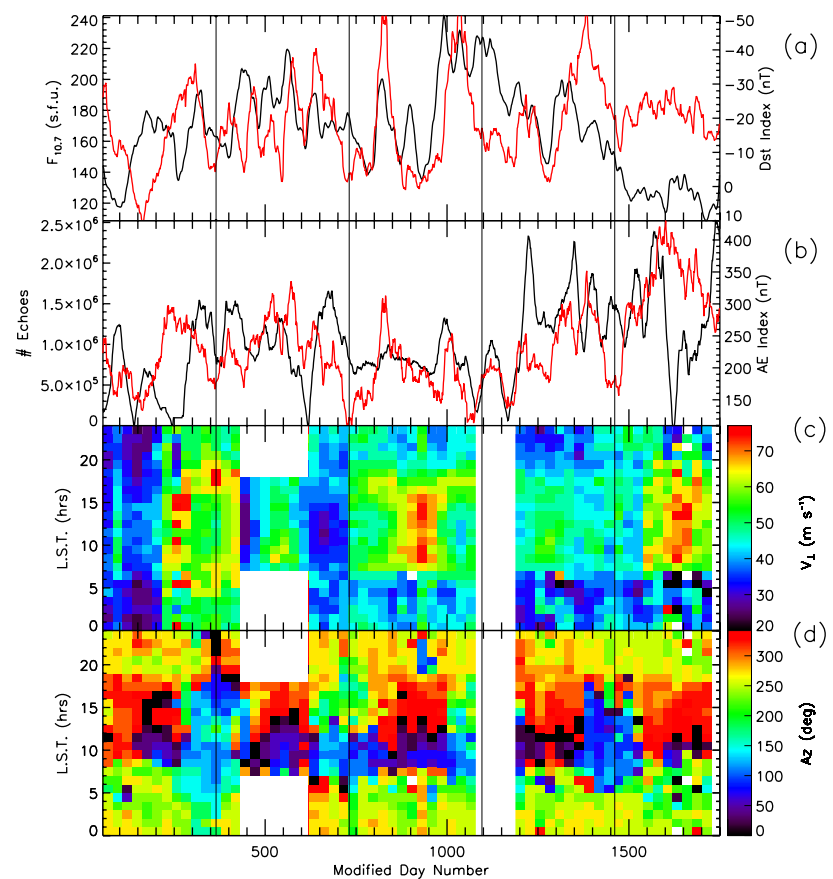

Fig. 1. Summary plot of the 5-year (1999-2003) database analysed in this study. The abscissa is modified day number (day $1=1 \mathrm{Jan}-$ uary 1999), the tick marks are at 50-day intervals, and the vertical lines across all panels delineate the start of each year. (a) 27-day running average of $10.7-\mathrm{cm}$ solar radio flux (black) and $D_{s t}$ index (red). (b) 27-day running count of DPS-4 echoes (black) and average AE index (red). (c) Colour map of the average of the velocity magnitudes perpendicular to the magnetic field, $V_{\perp}$. The bin size in LST is $1 \mathrm{~h}$. (d) The same as (c) except for the drift azimuths, $A_{z}$

from North $\left(0^{\circ}\right)$ through East $\left(90^{\circ}\right)$. The white space represents intervals of data rejected due to inevitable hardware and software problems. Averaged over the entire database, daytime $V_{\perp}$ was only $\sim 52 \mathrm{~m} \mathrm{~s}^{-1}$. During the austral winter months (June-August) daytime values of $V_{\perp}$ were larger ( $\sim 60 \mathrm{~m} \mathrm{~s}^{-1}$ ) and directed equatorward (purple, black, red), whilst during the summer months (December-February) daytime values $V_{\perp}$ were smaller $\left(\sim 45 \mathrm{~m} \mathrm{~s}^{-1}\right)$ and directed eastward and poleward (blue). Night time values of $V_{\perp}$ were generally smaller $\left(\sim 35 \mathrm{~m} \mathrm{~s}^{-1}\right)$ and directed westward (yellow), except during days 300-375 when they were equatorward (blue and black).

Another striking feature of Fig. 1c was the large increases in $V_{\perp}$ (red) for much of 2003 which coincided with the primary peak in the AE index. Likewise, the quietest interval during the 5-year campaign, days 100-200 and 700-750 had the lowest average night time values of $V_{\perp}\left(\sim 27 \mathrm{~m} \mathrm{~s}^{-1}\right)$ and they were directed poleward well into the evening (green). Overall, the main trends in our database are in reasonable agreement with seasonal variability observed at Millstone Hill (e.g. Buonsanto et al., 1993). 
(a)

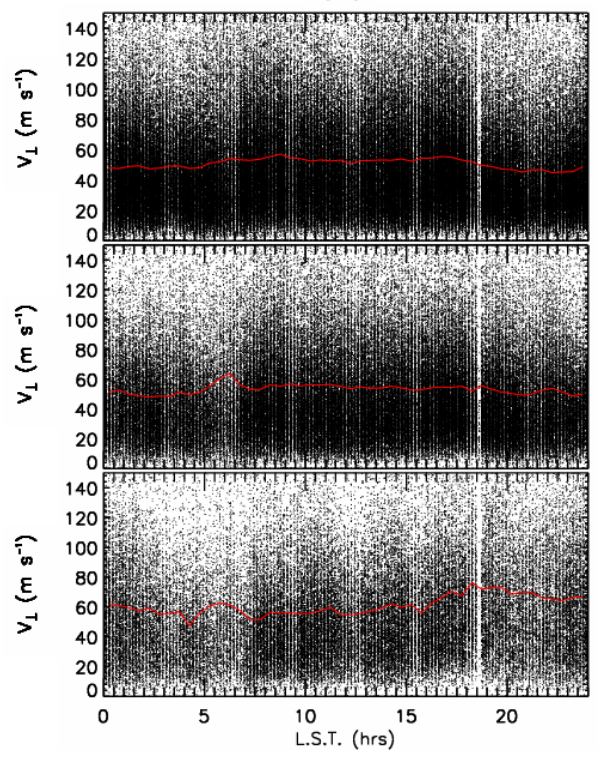

(b)

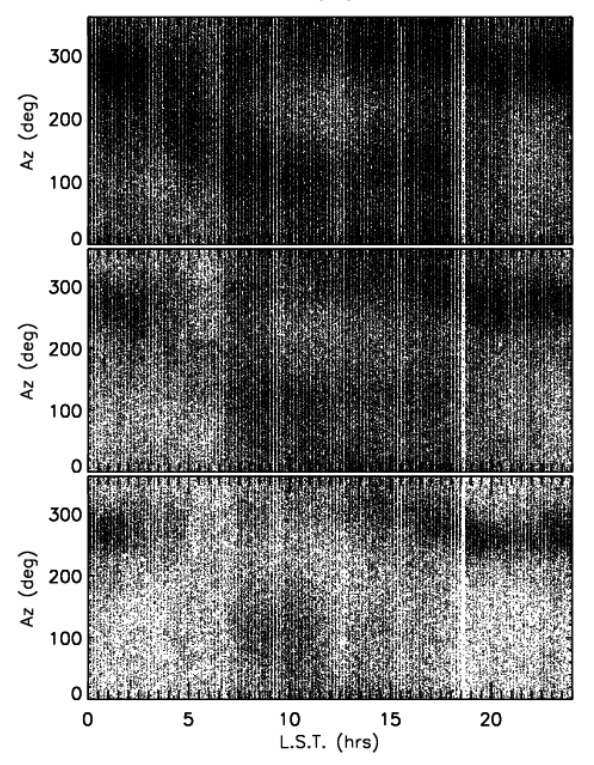

Fig. 2. Mass plot of (a) all drift velocity magnitudes perpendicular to the magnetic field, $\boldsymbol{V}_{\perp}$, and (b) drift directions perpendicular to the geomagnetic field, $A_{z}$, for geomagnetically quiet conditions $\mathrm{AE}<75 \mathrm{nT}$ (top); disturbed conditions $200 \mathrm{nT}<\mathrm{AE}<300 \mathrm{nT}$ (middle), and very disturbed conditions ( $\mathrm{AE}>500 \mathrm{nT}$ ) (bottom). The red curves show the 10-min running averages of $\boldsymbol{V}_{\perp}$. The vertical white stripe at $\sim$ 18:52 LST is due to daily internal calibrations used to correct any phase differences between the four receiver cards of the DPS-4. Local solar time (LST) corresponds to UT+09:40 h at Bundoora.

\section{Results}

In this section, we first examine the behaviour of individual velocities (i.e. without averaging) used to construct Fig. 1cd. Figure 2 shows mass plots of (a) all the F-region $V_{\perp}$ values and (b) drift directions perpendicular to the magnetic field lines, $\boldsymbol{A z}$. The top panels are for geomagnetically quiet conditions $(\mathrm{AE}<75 \mathrm{nT})$, the middle panels for disturbed conditions (200 $\mathrm{nT}<\mathrm{AE}<300 \mathrm{nT}$ ), and the bottom panels for very disturbed conditions $(\mathrm{AE}>500 \mathrm{nT}) . \mathrm{AE}=75 \mathrm{nT}$ is equivalent to $K_{p}=1$ and $500 \mathrm{nT}$ is comparable to $K_{p}=5$ (e.g. Starkov, 1994). Vertical striations in the mass plots arise due to the 2-min ionograms and daily internal calibration tests at 18:52 LST lasting for $8 \mathrm{~min}$.

Figure 2a indicates the quiet time $V_{\perp}$ values were generally enhanced during the daytime. As the magnetic activity increased, $V_{\perp}$ became larger during the afternoon and remained high during the night ( $\sim$ 15:00-03:00 LST). Figure $2 \mathrm{~b}$ shows the quiet-time azimuths formed a bifurcated distribution during the daytime, with the density of points maximising near $\sim 135^{\circ}$ (south east) and $\sim 330^{\circ}$ (north west). During the night time, the density of points maximised near the single westward direction $\sim 280^{\circ}$. As the level of geomagnetic activity increased, the daytime bifurcation was suppressed; the flows became mostly eastwards during 06:5012:00 LST, but strongly concentrated in a single westward direction for the remainder of the day.
The bifurcation of the drift azimuths during the daytime is largely explained by the variation in drift azimuths with season. Figure $1 \mathrm{~d}$ showed that the azimuths tended to alternate between preferred values during different seasons, especially during the daytime. The distribution of azimuths was complicated, but at about 13:00 LT, the azimuths alternated between preferred values of $\sim 135^{\circ}$ (blue) during the spring and summer months (September to February), and $\sim 330^{\circ}$ (red) during the remaining seasons. This is consistent with the overall bifurcation of azimuths shown in the mass plot for the entire data set, Fig. $2 b$.

Figure $2 \mathrm{~b}$ showed the bifurcation in azimuths tended to decrease with increasing $\mathrm{AE}$, implying the behaviour of the disturbance drifts was less influenced by season.

Digisondes are also sensitive to the Doppler shifts imparted by atmospheric gravity waves (AGWs) (Wright and Pitteway, 1982; Yuan et al., 2004). For low AE, there is a tendency for the mid-latitude ionosphere to drift very slowly, and the spectrum of AGW phase fronts may cause a large spread of drift directions. Despite this problem, the average quiet time drift resemble measurements made by midlatitude ISR (Parkinson et al., 2001). However, for high $\mathrm{AE}$, strong electric fields of magnetospheric origin impart a well-defined bulk motion in the overhead ionosphere, and the measured drifts predominantly represent $\boldsymbol{E} \times \boldsymbol{B} / B^{2}$ motion. Note that Digisonde measurements provide an excellent representation of convection velocity in the polar cap ionosphere (Smith et al., 1999). 


\subsection{Dependence of drift velocity on AE}

This section presents patterns of average plasma drift versus LST and geomagnetic activity. Figure 3 shows diurnal variations in (a) the magnitude of $V_{\perp}$, (b) $V_{\perp P}$, and (c) $V_{\perp E}$. The results are shown for geomagnetically quiet $(\mathrm{AE}<75 \mathrm{nT})$ (black) and very disturbed conditions (AE>500 nT) (red). The measurements have been averaged using 10-min bins. The error bars in this figure are standard errors, $\sigma / \sqrt{ } n$ where $\sigma$ is the standard deviation and $n$ is the number of samples.

Figure 3 a shows the quiet time velocity magnitudes maximised during the daytime, but the disturbed velocity magnitudes maximised in the dusk to midnight sector. The velocity magnitudes shown in all figures in this paper were calculated by averaging the velocity magnitudes calculated for each measurement separately, thereby providing an estimate representative of the magnitudes an instrument would measure from one instant to the next. As a result of this scalar summation, the velocity magnitudes are large. However, when calculating 10-min average field-perpendicular components (Fig. 3b and c), the large spread in drift directions caused relatively smaller velocity magnitudes.

Figure $3 \mathrm{~b}$ shows the quiet time $V_{\perp P}$ drifts were predominantly poleward in the early morning sector (up to $6 \mathrm{~m} \mathrm{~s}^{-1}$ ) and equatorward after about 09:00 LST (on average $7 \mathrm{~m} \mathrm{~s}^{-1}$ ). At night, the average amplitude of the meridional drifts was relatively low $\left(3 \mathrm{~m} \mathrm{~s}^{-1}\right)$ and tended to remain equatorward in the pre-mid night sector. The quiet time zonal drifts in Fig. 3c showed a more well-defined diurnal structure. $V_{\perp E}$ was eastward during 07:00-13:00 LST (up to $10 \mathrm{~m} \mathrm{~s}^{-1}$ ), stagnant during 13:00-18:00 LST, and predominantly westward during 18:00-07:00 LST (up to $18 \mathrm{~m} \mathrm{~s}^{-1}$ ).

During very disturb times (red curve), the meridional drifts became more equatorward during 02:00-07:00 and 12:0018:30LST, but more poleward during 18:30-01:30LST. However, on average, the perturbations in $V_{\perp P}$ due to increased magnetic activity were less than $2 \mathrm{~m} \mathrm{~s}^{-1}$. In contrast, zonal drifts had relatively larger perturbations, up to $32 \mathrm{~m} \mathrm{~s}^{-1}$ westward during the evening. These large perturbations are associated with disturbance dynamo electric fields, prompt penetration fields (Scherliess et al., 2001), and an equatorward expansion of the high-latitude convection pattern.

Referring to Fig. 3b-c, a poleward drift $V_{\perp P}$ is equivalent to an eastward directed electric field, $E_{\perp E}$ and an eastward drift $V_{\perp E}$ is equivalent to an equatorward directed electric field, $-E_{\perp P}$. The equivalent electric fields were calculated using a scaling of $1 \mathrm{mV} \mathrm{m}^{-1} \equiv 19.25 \mathrm{~m} \mathrm{~s}^{-1}$. For low AE index, the largest average eastward electric fields $\left(\sim 0.3 \mathrm{mV} \mathrm{m}^{-1}\right)$ occurred near sunrise (05:30 LST), whilst the largest westward electric fields $\left(\sim 0.6 \mathrm{mV} \mathrm{m}^{-1}\right.$ at 13:30 LST) occurred past local solar noon. The largest equatorward electric fields $\left(\sim 0.5 \mathrm{mV} \mathrm{m}^{-1}\right)$ occurred at 09:30 LST, whereas the largest poleward fields $\left(\sim 1.8 \mathrm{mV} \mathrm{m}^{-1}\right)$ occurred near dusk.

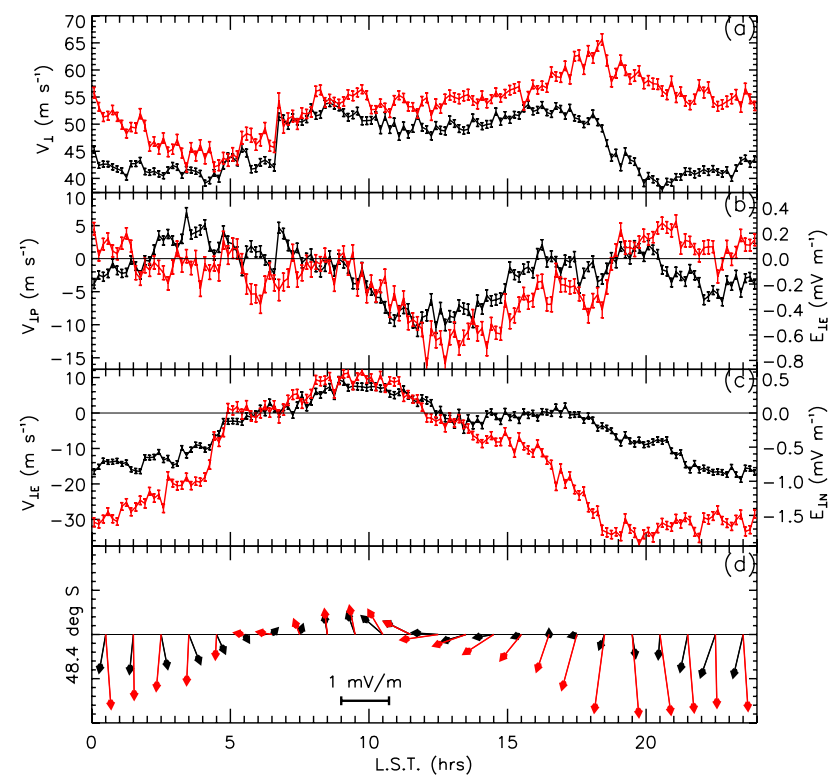

Fig. 3. Diurnal patterns of F-region drift and equivalent electric field during geomagnetically quiet conditions $(\mathrm{AE}<75 \mathrm{nT}$ ) (black) and very disturbed conditions (AE $>500 \mathrm{nT})$ (red) for (a) the velocity magnitudes, $V_{\perp}$, (b) the field-perpendicular motion in the poleward direction, $\boldsymbol{V}_{\perp P}$, and (c) the field-perpendicular motion in the eastward direction, $V_{\perp E}$. (d) Feather plot of the equivalent fieldperpendicular electric field vectors where the poleward direction is downward and the eastward direction is to the right.

Figure $3 d$ is a feather plot of the equivalent electric field vectors versus LST where equatorward vectors point upward and eastward vectors point toward the right in the plot. The magnitudes and directions of these vectors were calculated using the numbers shown in Fig. $3 b$ and c. The electric field magnitudes exhibit a quasi-sinusoidal diurnal pattern with a quiet time (black) maximum at $\sim 22: 30 \mathrm{LST}$ and corresponding minimum at $\sim 16: 30 \mathrm{LST}$. The electric field magnitudes ranged from $\sim 0.2-1.2 \mathrm{mV} \mathrm{m}^{-1}$ for low $\mathrm{AE}$ index, but reached more than $3 \mathrm{mV} \mathrm{m}^{-1}$ under very disturbed conditions near 20:00 LST. The electric field magnitudes were weakly enhanced with increased magnetic activity during 05:30-10:30 LST, while at other times the amplification factor ranged from $2-4$.

Figure 3 sorted the entire 5-year database according to two broad categories of $\mathrm{AE}$ index and this did not reveal gradual variations of drift velocity with increasing $\mathrm{AE}$ index. In Fig. 4 , the velocity magnitudes, $V_{\perp}$, and velocity components, $V_{\perp P}$ and $V_{\perp E}$ have been sorted using 20-min bins of LST and 50-nT bins of the AE index. These bin sizes were chosen to give at least 500 samples per bin, thereby maintaining the statistical significance of the results. For $\mathrm{AE}>1000 \mathrm{nT}$, the number of data points per bin seldom exceeded the threshold of 500 samples.

Consistent with Fig. 3a, Fig. 4a shows that the velocity magnitudes peaked during the daytime for quiet to 


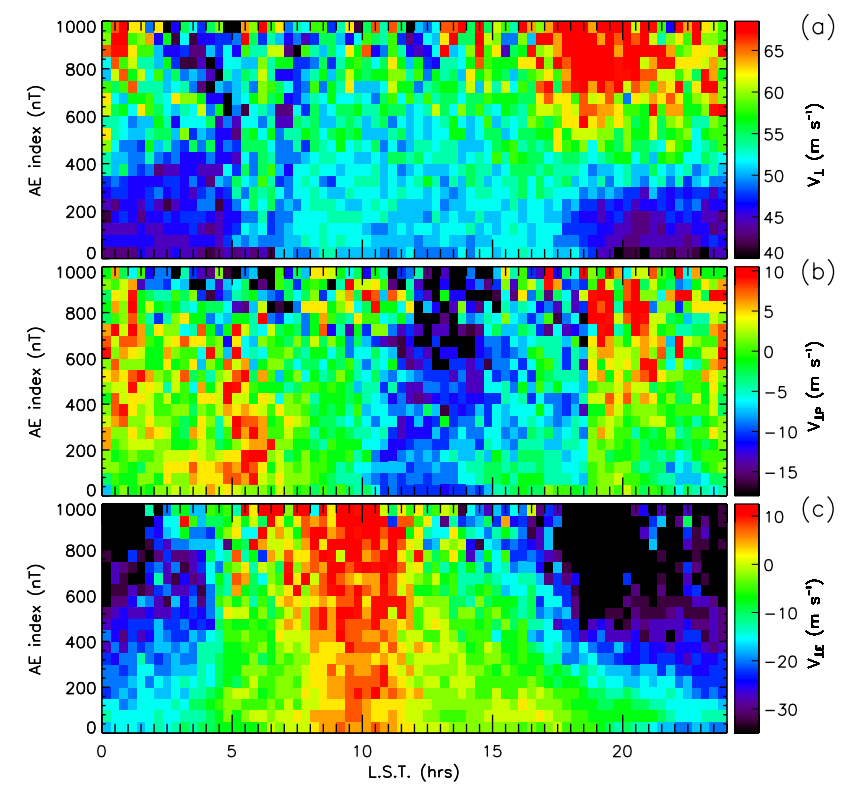

Fig. 4. Colour map showing the variation of (a) velocity magnitudes $V_{\perp}$, (b) $V_{\perp P}$, and (c) $V_{\perp E}$ with LST and AE index for the entire 5 -year database. The velocities were averaged using bin sizes of 20-min in LST and $50 \mathrm{nT}$ in AE index.

moderately disturbed conditions ( $\mathrm{AE}<400 \mathrm{nT})$, but during the dusk to midnight sector for very disturbed conditions $(\mathrm{AE}>500 \mathrm{nT})$. There is a suggestion that the velocity magnitudes actually peaked at $\sim 08: 30$ and 16:00 LST during very quiet conditions.

Figure $4 \mathrm{~b}$ shows that the plasma flow was strongly poleward near sunrise ( $\sim 05: 00 \mathrm{LST})$ for quiet conditions. This flow pattern was no longer evident for $\mathrm{AE}>\sim 600 \mathrm{nT}$ and tended to become weakly equatorward for extreme $\mathrm{AE}$ values. During $\sim 12: 00-18: 30$ LST the flow was weakly equatorward for quiet conditions and became enhanced for $\mathrm{AE}>600 \mathrm{nT}$. In the evening sector beyond $\sim 18: 30 \mathrm{LST}$, the normally weak equatorward flow was replaced by weak poleward flow for $\mathrm{AE}>600 \mathrm{nT}$. A small discontinuity around 19:00 LST in Fig. 4b arises from the day-to-night switching in the fixed frequency sounding and thus a change in reflection height in the ionosphere.

Figure $4 \mathrm{c}$ indicates strong, clearly defined changes in zonal flow with $\mathrm{AE}$ index. As the $\mathrm{AE}$ index increased, the normally weak eastward flows near 10:00 LST were enhanced, and the westward flows during the night sector were strongly enhanced. There was a tendency for the westward flows to begin earlier in the day (before 16:00 LST) under very disturb conditions. This implies the corresponding radial electric field in the inner magnetosphere migrates Earthward and toward dusk during geomagnetically disturbed conditions.

Surprisingly, the enhancement of westward flow penetrated furthest into the early morning sector for $\mathrm{AE} \sim 600 \mathrm{nT}$,

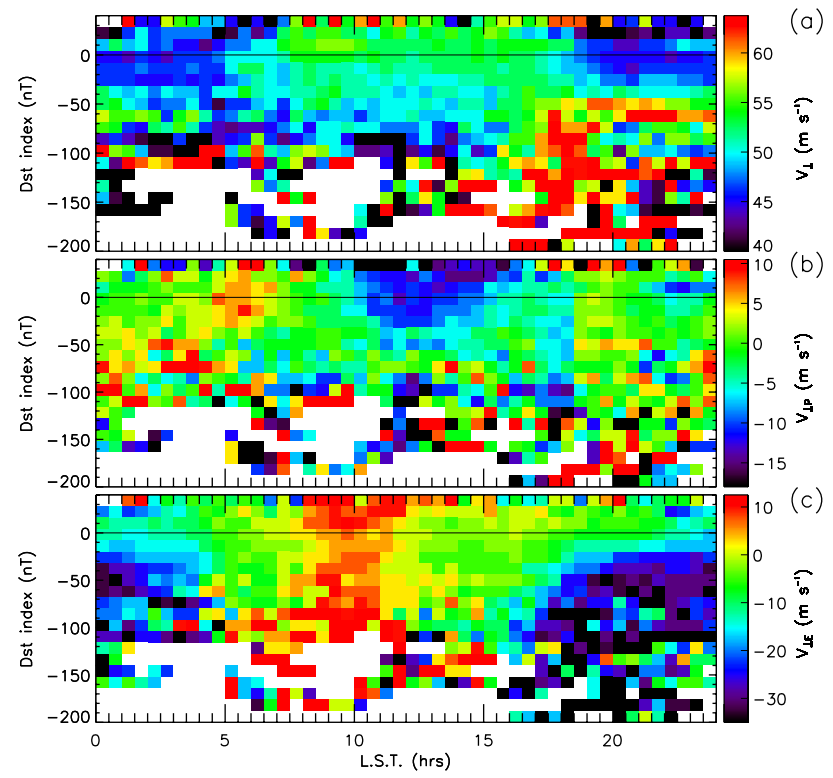

Fig. 5. Colour map showing the variation of (a) velocity magnitudes $V_{\perp}$, (b) $V_{\perp P}$, and (c) $V_{\perp E}$ with LST and $D_{s t}$ index for the entire 5-year database. The velocities were averaged using bin sizes of $20 \mathrm{~min}$ in LST and $7 \mathrm{nT}$ in $D_{s t}$.

whilst for smaller and larger $\mathrm{AE}$ values the enhancement had a shorter duration. Also, maximum perturbations in the velocity components occurred in the local afternoon sector (16:00-18:00 LST), whereas analysis using 3-hourly $K_{p}$ index found maximum perturbations later in the evening (Parkinson et al., 2001).

\subsection{Dependence of drift velocity on $D_{s t}$}

This section presents patterns of average plasma drift versus LST and geomagnetic activity, as measured by the $D_{s t}$ index. To first order, the $D_{s t}$ index is a measure of magnetospheric ring current activity which intensifies during geomagnetic storms.

Figure 5 is in the same format as Fig. 4, except it sorts the velocities according to 7-nT bins of $D_{s t}$. There is considerable scatter in the velocities for the most negative values of $D_{s t}$ partly because large storms are rare. Also, a review of ionograms confirmed that the equatorward expansion of the main trough or negative storm effects tended to force $f o \mathrm{~F} 2$ below the fixed frequency chosen for drift measurements, further reducing the number of echoes for the most negative $D_{s t}$ values.

Some significant trends are apparent in Fig. 5 despite the limited number of samples. Similar to the results for the AE index (Fig. 4a), the velocity magnitudes maximised during the daytime for quiet conditions $\left(D_{s t} \sim 0 \mathrm{nT}\right)$, and in the dusk to midnight sector for disturbed conditions $\left(D_{s t}<-40 \mathrm{nT}\right)$.

The main feature in Fig. $5 b$ is a decrease in the local time extent of dayside equatorward flows with decreasing 
$D_{s t}$. That is, the flows were equatorward during $\sim 10: 00$ to 18:00 LST for $D_{s t} \sim 0 \mathrm{nT}$, but became near zero or noiselike for $D_{s t}$ between $-30 \mathrm{nT}$ and $-60 \mathrm{nT}$. This is contrary to the results found for the AE index (Fig. 4a-b) which showed the flows became more strongly equatorward with increasing AE.

On the other hand, Fig. 5c shows the relationship between zonal drifts and the $D_{s t}$ index was similar to that found for zonal drifts and the AE index (Fig. 4c). That is, the westward drifts were strongly enhanced in the night sector when $\mathrm{AE}$ increased or $D_{s t}$ decreased.

Statistical results from earlier works suggest that the effect of the initial phase of a storm has a low probability of affecting a mid-latitude station in the night sector (e.g. Hargreaves, 1992; Buonsanto, 1999). The results for positive $D_{s t}$ in Fig. 5 are not necessarily for storm sudden commencement, but there is a suggestion that equatorward and eastward flows may have occurred at storm commencement during the day time interval $\sim 09: 00-16: 00$ LST.

\subsection{Dependence of drift velocity on $10.7-\mathrm{cm}$ solar flux}

This section presents patterns of average plasma drift versus LST and solar activity, as measured by the F10.7-cm solar radio flux, a widely accepted proxy for the 11/22-year Hale cycle of magnetic activity. Figure 6 is in the same format as Figs. 4-5, except it sorts the average velocity components according to 20 -min bins of LST and $8 \times 10^{-22} \mathrm{~W} \mathrm{~m}^{-2} \mathrm{~Hz}^{-1}$ bins of solar radio flux. No results for solar flux levels below $100 \times 10^{-22} \mathrm{~W} \mathrm{~m}^{-2} \mathrm{~Hz}^{-1}$ are shown because relatively few days of low solar activity occurred throughout the study interval 1999-2003.

Variations in the drift velocity with solar radio flux are expected to be weaker than variations with indices of geomagnetic activity because only some reconfigurations of the solar magnetic field will directly impact Geospace. Changes in the solar wind speed are thought to be a better indicator of the effects of the Hale cycle on Geospace, including those variations with $\mathrm{AE}$ index which have already been shown.

Figure 6a shows that for all solar flux levels, the velocity magnitudes peaked during the day time. The lowest velocity magnitudes tended to occur in the morning sector for $\mathrm{F} 10.7 \mathrm{~cm}<120 \times 10^{-22} \mathrm{~W} \mathrm{~m}^{-2} \mathrm{~Hz}^{-1}$, and the largest velocity magnitudes tended to occur during the daytime for the same moderate levels of activity. The velocity magnitudes peaked at $\sim 08: 30$ and 16:00 LST for solar flux levels greater than $140 \times 10^{-22} \mathrm{~W} \mathrm{~m}^{-2} \mathrm{~Hz}^{-1}$.

To first approximation, Fig. $6 \mathrm{~b}$ suggests the daytime equatorward drift weakened for large solar flux during the interval 10:00-18:00 LST. Perhaps the equatorward drift intensified again for very large solar flux $\left(>220 \mathrm{~W} \mathrm{~m}^{-2} \mathrm{~Hz}^{-1}\right)$. There was also a weak tendency for the drifts to become more poleward during the night sector $\sim 18: 00-05: 00$ LST. The strongest feature of Fig. 6c was the tendency for enhanced night-time west-

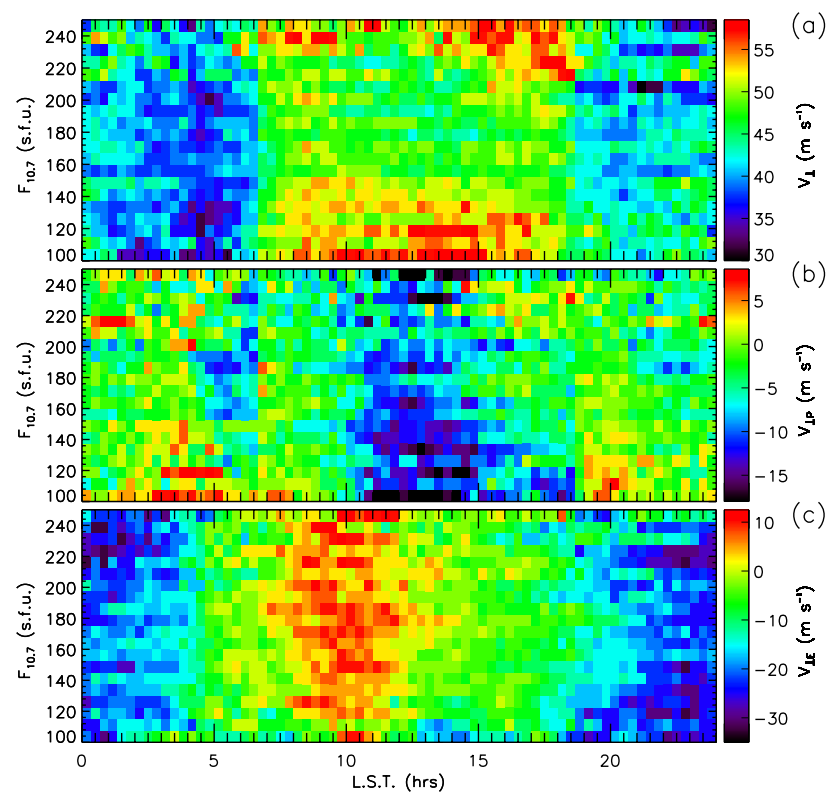

Fig. 6. Colour map showing the variation of (a) velocity magnitudes $V_{\perp}$, (b) $V_{\perp P}$, and (c) $V_{\perp E}$ with LST and 10.7-cm solar flux for the entire 5-year database. The averages were calculated using bin sizes of $20 \mathrm{~min}$ in LST and $8 \times 10^{-22} \mathrm{~W} \mathrm{~m}^{-2} \mathrm{~Hz}^{-1}$ in solar flux. Note that 1 s.f.u. $=10^{-22} \mathrm{~J} \mathrm{~s}^{-1} \mathrm{~m}^{-2} \mathrm{~Hz}^{-1}$.

ward drifts for both lower $\left(<130 \mathrm{~W} \mathrm{~m}^{-2} \mathrm{~Hz}^{-1}\right)$ and higher $\left(>220 \times 10^{-22} \mathrm{~W} \mathrm{~m}^{-2} \mathrm{~Hz}^{-1}\right)$ solar flux, but less so for intermediate values.

Overall, the variations in the drift velocity with solar flux, in particular the meridional components, more closely resemble the results found for the $D_{s t}$ index, which is consistent with the weak correlation between solar flux and $D_{s t}$ shown in Fig. 1a.

\section{Discussion}

\subsection{Quiet-time mid-latitude F-region drifts}

Quiet-time mid- and low-latitude ionospheric drifts are driven by E- and F-region dynamo electric fields (Fejer, 1993). Daytime electric fields are mainly produced by solar differential heating which excites tidal winds and forces the plasma across geomagnetic field lines, thus generating the E-region dynamo (e.g. Fejer, 1993; Richmond et al., 1976). This dynamo electric field together with the thermospheric neutral winds generates a large-scale vortex current over the mid and low-latitude ionospheres known as the Sq current system. It is well established that the Sq current system exhibits a semidiurnal pattern in regions with magnetic dip angle of $20^{\circ}-70^{\circ}$ (Kelley, 1989).

F-region polarization electric fields on the dayside are short-circuited by the highly conducting E-region (Fejer, 1993; Buonsanto et al., 1993). When the E-region electron 
densities decay at night, the F-region dynamo becomes important, and for high mid-latitude stations, it can be strongly affected by upper thermospheric neutral winds of auroral origin.

At high latitudes, the electric potential is bounded by the two-cell plasma convection pattern, but the neutral winds remain unbounded. A flywheel type effect occurs with winds blowing out of the auroral oval at all times (Kelley, 1989). Once equatorward of the oval, the Earth's Coriolis force subsequently deflects the winds toward the west, forcing the neutrals and ions to move in the same direction. These winds generate polarization electric fields, which strongly affect night-time ionospheric plasma drifts in the mid- to highlatitude transition zone.

Quiet-time meridional drifts (zonal electric fields) measured during the day at Bundoora ( $49^{\circ} \mathrm{S}$ magnetic) exhibit a clear semidiurnal variation portraying the $\mathrm{E}$ region dynamo effect. The flow is poleward in the morning and equatorward later during the day. Similar N-S component variations have been reported for other mid-latitude stations, namely Millstone Hill (57 $\mathrm{N}$ magnetic) (Buonsanto and Witasse, 1999); Saint-Santin $\left(40^{\circ} \mathrm{N}\right.$ magnetic) (Buonsanto et al., 1993) and Arecibo ( $31^{\circ} \mathrm{N}$ magnetic) (Fejer, 1993). Note that Bundoora is located midway between Saint-Santin and Millstone Hill in terms of magnetic latitude, but geographically it is closer to the equator than both stations.

The daytime zonal drifts (meridional electric fields) do not show a well defined reversal as would be caused by the Eregion dynamo. The striking feature of the Bundoora zonal drifts, especially in the night sector, is their close resemblance to Millstone Hill drifts, yet limited agreement with measurements reported from Saint-Santin and Arecibo stations. This is to be expected since both Bundoora and Millstone Hill are high mid-latitude stations and their drifts are likely to be driven by similar processes. However, we expect the Bundoora velocity magnitudes to be somewhat smaller at Bundoora because effects emanating from the high-latitude ionosphere are expected to decay with decreasing latitude toward the equator.

During the night time, the electric field vectors (Fig. 3d) were polewards, in agreement with the direction of auroral and sub-auroral electric fields in the pre-midnight to midnight sector (Kelley, 1989). Hence, even during relatively quiet intervals, the zonal drifts of high mid-latitude stations such as Bundoora (i.e. $\sim 49^{\circ}$ magnetic or more) are influenced by auroral effects particularly in the night sector (e.g. Richmond et al., 1980). Like all mid-latitude stations, Bundoora tends to be furthest from the auroral oval during the daytime; hence the zonal drifts are only weakly westward, or they even become briefly eastward before midday (Fig. 3c). At Saint-Santin and Aercibo, these influences only become evident during disturbed periods (Blanc, 1983; Fejer, 1993).

\subsection{Disturbed F-region drifts}

The ionospheric disturbance dynamo is a well-known cause of the perturbation drifts observed at mid- and low-latitude stations including Bundoora ( $49^{\circ}$ magnetic). The disturbance dynamo is produced by the equatorward surge of thermospheric winds when there is heating of the auroral ionosphere by enhanced energy and momentum deposition (Blanc and Richmond, 1980). The disturbance dynamo drives poleward drift (eastward electric field) through the night and equatorward drift (westward electric field) during the day. The expected directions of the perturbation drifts are in agreement with the perturbation drifts observed at Bundoora (Fig. 4b, c).

The meridional transport of angular momentum by the equatorward surge of storm-time thermospheric winds combined with the action of the Coriolis force produces westward winds and plasma drifts at mid-latitudes. The Bundoora measurements show clear evidence for westward drift enhancement (poleward electric field) during the late afternoon and evening with increasing AE and $D_{s t}$ index (Figs. $4 \mathrm{c}$ and $5 \mathrm{c}$ ). Dynamo theory predicts large short-lived eastward drifts at high-latitudes in the early morning sector (Blanc and Richmond, 1980). Like the Millstone Hill ISR, the Bundoora Digisonde also observes eastward perturbation drifts during the morning sector (07:00-12:00 LST).

The region of strongly enhanced westward plasma convection observed immediately equatorward of the auroral oval in the dusk to night sector is commonly referred as the subauroral ion drift (SAID) (e.g. Anderson et al., 1991) or subauroral polarization stream (SAPS) (e.g. Foster and Burke, 2002). Associated with this narrow region of strong convection is the main F-region ionospheric trough (Foster and Rich, 1998). As the magnetic activity increases, the SAPS region moves equatorward from high latitudes $\left(\sim 64^{\circ} \Lambda\right)$ to mid latitudes $\left(\sim 52^{\circ} \Lambda\right)$. The width of the SAPS can be $\sim 3-$ $5^{\circ} \Lambda$ (Foster and Vo, 2002). Plasma flow on the equatorward edge of SAPS is always westwards and becomes more westward as the latitude increases (e.g. Anderson et al., 1991).

Except during extreme geomagnetic storms, Bundoora $\left(50^{\circ} \Lambda\right)$ will be located equatorward of high-latitude convection zone, including the SAPS and associated ionization trough. However, it will be influenced by the westward flows found immediately equatorward of the region, and this influence will be greater during major geomagnetic activity. The eastward convection in the high-latitude dawn convection cell will also expand equatorward during major geomagnetic activity. Thus some of the perturbation drifts observed at Bundoora will be caused by an equatorward expansion of the high-latitude convection zone.

Global convection models have demonstrated that the inner edge of the plasma sheet and the associated Region2 field aligned current system cannot fully shield the midand low-latitude ionosphere and plasmasphere from magnetospheric convection electric fields (Scherliess and Fejer, 
1998). The electric fields which penetrate due to under- and over-shielding lead to large departures from the quiet time ionospheric dynamo and they drive stronger ionospheric bulk motions. During under-shielding conditions, a sudden increase in AE index causes an instantaneous enhancement in poleward drift (eastward electric field) on the dayside and equatorward drift (westward electric field) on the night side at lower latitudes (Fejer, 2002). Conversely, during overshielding conditions, a sudden decrease in AE index leads to an equatorward drift on the dayside and poleward drift at night. Similar intrinsic time scales are expected for the effects of under- and over-shielding.

Figure $4 \mathrm{~b}, \mathrm{c}$ sorted the Bundoora velocity components according to the $\mathrm{AE}$ index and they basically showed an equatorward enhancement (westward electric field) during the day and a poleward enhancement (eastward electric field) at night. These responses are opposite to the directions expected for under shielding, but in the same direction expected for over shielding. However, when averaging a large data set, the effects of under- and over-shielding will interfere in a complicated way versus LT. The effects of prompt penetration fields need to be identified using time series analysis, and it is not clear how they affect the present results.

It should be realised that the response of the ionosphere to storms is dependent on a number of variables, such as local time and location of station, the storm onset time, the storm duration, storm intensity and pre-storm conditions (e.g. Buonsanto, 1999). Further, the coupled magnetosphereionosphere system is thought to exist in different modes for storms and substorms. Storms, for example, are distinguished by major increases in the equatorial ring current and sometimes a persistent increase in the radiation belt particles during the recovery phase. Thus, it is not surprising that the averaged Bundoora ionospheric drifts, in particular the meridional components, exhibited different behaviour when sorted according to the $\mathrm{AE}$ and $D_{s t}$ indices.

\section{Summary and future work}

Digisonde drift velocity data gathered during the 5 year interval 1999-2003 at the southern mid-latitude station Bundoora $\left(49^{\circ} \mathrm{S}\right.$ magnetic) was used to study variability in F-region ionospheric electric fields. Our results more fully quantify the response of the mid-latitude ionosphere to changing solar and geomagnetic conditions, as is required to help refine empirical and theoretical models of mid-latitude electric fields. The main results of this study are summarised as follows:

1. The bifurcation of drift azimuths shown in the mass plot Fig. $2 b$ largely arose from seasonal and day-to-day variations in the preferred azimuths (Fig. 1d). Because Fig. $2 b$ showed the bifurcation in azimuths tended to decrease with increasing AE, we infer the behaviour of the disturbance drifts was less influenced by season. The effects of AGWs on the Doppler shift measurements may have also contributed to the observed spread of drift directions.

2. The magnitude of the velocities perpendicular to magnetic field, $V_{\perp}$, exhibited strong diurnal patterns. They tended to maximise during the daytime for geomagnetically quiet conditions, but during the dusk to midnight sector for disturbed conditions. In general, the velocity magnitudes tended to increase with $\mathrm{AE}$ index, and they maximised during the morning and afternoon for $\mathrm{F} 10.7 \mathrm{~cm}>140 \mathrm{~W} \mathrm{~m}^{-2} \mathrm{~Hz}^{-1}$. They were relatively larger in austral winter months (June-August) and for the declining phase of solar activity cycle (2003).

3. When sorted according to the AE index, the perturbations in the meridional drifts tended to be equatorward in the day and poleward at night. However, they became less poleward for $\mathrm{AE}>600 \mathrm{nT}$ during 04:00-07:00 LST. When sorted according to the $D_{s t}$ index, the meridional drifts behaved in a similar way, except the daytime equatorward flows strengthened with increasing AE index, whereas they weakened for $D_{s t}<-60 \mathrm{nT}$. When sorted according to the F10.7 cm solar flux, equatorward flows were also weak for values $>160 \times 10^{-22} \mathrm{~W} \mathrm{~m}^{-2} \mathrm{~Hz}^{-1}$.

4. When sorted according to the AE index, perturbations in the zonal drifts tended to be weakly eastward during the morning, and strongly westward during the night. As $\mathrm{AE}$ increased, the westward perturbation drifts tended to start earlier in the afternoon, and they persisted longer into the evening sector. However, they only extended further into the morning sector for intermediate values of $\mathrm{AE}(\sim 600 \mathrm{nT})$. The westward drifts were also strongly enhanced during the night with decreases in the $D_{s t}$ index, but they were most enhanced during the night for smaller values of the $\mathrm{F} 10.7 \mathrm{~cm}$ index.

5. The geomagnetically quiet and disturbed patterns of ionospheric drift are explained by the combined effect of three familiar mechanisms:

(a) The quiet time ionospheric dynamo driven by solar thermospheric tides and thermospheric winds emanating from the high-latitude ionosphere (e.g. the cross polar jet) influence the quiet time drifts observed at Bundoora. Thermospheric winds emanating from the auroral regions are enhanced during geomagnetic disturbances and produce the disturbance dynamo which exerts a major influence on the Bundoora drifts.

(b) The strong ionospheric convection found at high latitudes has a practical equatorward limit but the large westward drifts found in the subauroral ionosphere (for example) decay moving equatorward through the mid-latitude ionosphere. During extreme geomagnetic disturbances, the high-latitude 
convection pattern expands equatorward and its equatorward edge extends into the mid-latitude ionosphere above Bundoora.

(c) There is no doubt that prompt penetration electric fields due to under and over shielding conditions affect the drift velocities observed at Bundoora, but their effects are difficult to distinguish in the simple averages reported here.

The Bundoora Digisonde is located in a favourable location for monitoring the effects of enhanced geomagnetic activity on the mid-latitude ionosphere, and the present results will help to refine empirical and theoretical models of midlatitude electric fields. However, this study did not separate out the different causes the perturbation drifts listed above, and establish their relative importance. Superposed analysis techniques could be applied to the Bundoora measurements to separate out the time history of the different contributions as a function of substorm and storm phase, and the local time of onset.

Clearly, co-ordinated observations over extended regions of longitude and latitude are also required to achieve a more complete understanding of the physical mechanisms involved. We anticipate the next major advance will arise from an analysis of extensive observations made by the new SuperDARN radars recently deployed at mid-latitudes because of their ability to simultaneously map ionospheric irregularities and Doppler shifts across vast spatial regions.

Acknowledgements. This work was supported by an internal research grant awarded by La Trobe University. Financial support for Vickal V. Kumar was provided by an Australian Government Endeavour Postgraduate Award (ESPA_DCD_365_2007).

Topical Editor M. Pinnock thanks two anonymous referees for their help in evaluating this paper.

\section{References}

Anderson, P. C., Heelis, R. A., and Hanson, W. B.: The ionospheric signatures of rapid subauroral ion drifts, J. Geophys. Res., 96, 5785-5792, 1991.

Behnke, R. A. and Harper, R. M.: Vectors measurements of F region ion transport at Arecibo, J. Geophys. Res., 78, 8222-8234, 1973.

Blanc, M.: Magnetospheric convection at mid-latitudes 3: theoretical derivation of the disturbance convection pattern in the plasmasphere, J. Geophys. Res., 88, 235-251, 1983.

Blanc, M. and Richmond, A. D.: The ionospheric disturbace dynamo, J. Geophys. Res., 85, 1669-1686, 1980.

Buonsanto, M. J.: Ionospheric storms - a review, Space Sci. Rev., 88, 563-601, 1999.

Buonsanto, M. J., Hagan, M. E., Salah, J. E., and Fejer, B. G.: Solar cycle and seasonal variations in $\mathrm{F}$ region electrodynamics at Millistone hill, J. Geophys. Res., 98, 15 677-15 683, 1993.

Buonsanto, M. J. and Witasse, O. G.: An updated climatology of thermospheric neutral winds and F region ion drifts above Millstone Hill, J. Geophys. Res., 104, 24 675-24 687, 1999.
Cliver, E. W., Boriakoff, V., and Bounar, K. H.: The 22-year cycle of geomagnetic and solar wind activity, J. Geophys. Res., 101, 27 091-27 109, 1996.

Evans, J. V.: Measurements of horizontal drifts in the $\mathrm{E}$ and $\mathrm{F}$ region at Millstone Hill, J. Geophys. Res., 77, 2341-2352, 1972.

Fejer, B. G.: F region plsama drifts over Arecibo: solar cycle, seasonal and magnetic acitivity effects, J. Geophys. Res., 98, 645652, 1993.

Fejer, B. G.: Low latitude storm time ionospheric electrodynamics, J. Atmos. and Solar-Terr. Phys., 64, 1401-1408, 2002.

Fejer, B. G., Emmert, J. T., Shepherd, G. G., and Solheim, B.: Average daytime $F$ region disturnbance neutral winds measured by UARS: Initial results, Geophys. Res. Lett., 27, 1859-1862, 2000.

Foster, J. C. and Burke, W. J.: SAPS: a new characterization for sub-auroral electric fields, EOS, 83, 393-394, 2002.

Foster, J. C. and Rich, F. J.: Prompt mid-latitude electric field effects during severe geomagnetic storms, J. Geophys. Res., 103, 26367-26372, 1998.

Foster, J. C. and Vo, H. B.: Average characteristics and activity dependence of subauroral polarization stream, J. Geophys. Res., 17, 1475, doi:10.1029/2002JA009409, 2002.

Hargreaves, J. K.: The solar-terrestrial environment, Cambridge University Press, Cambridge, 1992.

Heelis, R. A.: Electrodynamics in the low and middle latitude ionosphere: a tutorial, J. Atmos. Solar-Terr. Phys., 66, 825-838, 2004.

Kelley, M. C.: The earth's ionosphere, Academic Press, California, 1989.

Parkinson, M. L., Breed, A. M., Dyson, P. L., and Morris, R. J.: Application of the dopplionogram to doppler-sorted interferometry measurements of ionospheric drift velocity, Radio Sci., 34, 899-912, 1999.

Parkinson, M. L., Polglase, R., Fejer, B. G., Scherliess, L., Dyson, P. L., and Ujmaia, S. M.: Seasonal and magnetic activity variations of ionospheric electric fields above the southern mid-latitude station, Bundoora, Australia, Ann. Geophys., 19, 521-532, 2001, http://www.ann-geophys.net/19/521/2001/.

Reinisch, B. W.: New technique in ground-based ionospheric sounding and studies, Radio Sci., 21, 331-341, 1986.

Richmond, A. D., Blanc, M., Emery, B. A., Wand, R. H., Fejer, B. G., Woodman, R. F., Ganguly, S., Amayenc, P., Behnke, R. A., Calderon, C., and Evans, J. V.: An empirical model of quiet-day electric fields at middle and low-latitudes, J. Geophys. Res., 85, 4658-4664, 1980.

Richmond, A. D., Matsushita, S., and Tarpley, J. D.: On the production mechanism of electric currents and fields in the ionosphere, J. Geophys. Res., 81, 547-555, 1976.

Scali, J. L.: A quality control package for the digisonde drift analysis (DDA), Tech, Rep. TR-93-2220, http://umlcar.uml.edu, 1993.

Scali, J. L., Reinisch, B. W., Heinselman, C. J., and Bullet, T. W.: Coordinated digisonde and incoherent-scatter radar F-region drifts measurements at sondre Stromfjord, Radio Sci., 30, 14811498, 1995.

Scherliess, L. and Fejer, B. G.: Satellite studies of mid and lowlatitude ionospheric disturbance zonal plasma drifts, Geophys. Res. Lett., 25, 1503-1506, 1998.

Scherliess, L., Fejer, B. G., Holt, J., Goncharenko, L., AmoryMazaudier, C., and Buonsanto, M. J.: Radar studies of midlatitude ionospheric plasma drifts, J. Geophys. Res., 106, 1771- 
1784, 2001.

Smith, P. R., Dyson, P. L., Monselesan, D. P., and Morris, R. J.: Ionospheric convection at Casey, a southern polar cap station, $\mathrm{J}$. Geophys. Res., 103, 2209-2218, 1998.

Spiro, R. W., Wolf, R. A., and Fejer, B. G.: Penetration of highlatitude-electric-feild effects to low latitudes during SUNDIAL 1984, Ann. Geophys., 6, 35-50, 1988, http://www.ann-geophys.net/6/35/1988/.

Starkov, G. V.: Statistical dependence between the magnetic activity indices, Geomagnetism Aeronomy, 34(1), 101-103, 1994.

Vo, H. B. and Foster, J. C.: A quantitative study of ionospheric density gradients at mid-latitudes, J. Geophys. Res., 106, 21 55521564,2001
Wand, R. H. and Evans, J. V.: The penetration of convection electric fields to the latitude of Millstone Hill, J. Geophys. Res., 86, 5809-5814, 1981.

Weimer, D. R.: Models of high latitude electric potentials derived with a least error fit of spherical harmonic coefficients, J. Geophys. Res., 100, 19595-19607, 1995.

Wright, J. W. and Pitteway, M. L. V.: Application of Dopplionograms and Gonionograms to atmospheric gravity-wave disturbances in the ionosphere, J. Geophys. Res., 87, 1719-1721, 1982.

Yuna, Z., Ning, B., Wan, W., and Yuan, H.: Acquirement and analysis of Doppler ionograms with high accuracy in the ionogram mode from Digisonde 256, Radio Sci., 39, RS2021, doi:10.1029/2002RS002779, 2004. 